\title{
论文
}

\section{青藏高原草原带和荒漠带湖泊表层沉积物现代 花粉研究}

\author{
秦锋* \\ 中国科学院地理科学与资源研究所陆地表层格局与模拟院重点实验室, 北京 100101 \\ * 通讯作者, E-mail: qinfeng@igsnrr.ac.cn
}

收稿日期: 2020-05-19; 收修改稿日期: 2020-09-21; 接受日期: 2020-10-21; 网络版发表日期: 2021-01-21

国家自然科学基金项目(批准号: 41671202, 41690113)、中国科学院战略性先导科技专项项目(编号: XDA20070101)和国家重点研发计划项目 (编号: 2016YFA0600501)资助

\begin{abstract}
摘要花粉现代过程研究是基于化石花粉谱重建古植被和古气候变化的基础. 尽管青藏高原已经有大量花粉现 代过程研究, 但是仅有少数关于湖泊表层沉积物现代花粉组合的报道. 本研究分析了青藏高原草原带和荒漠带34 个湖泊的表层沉积物花粉组合，结果显示，这两个高原植被带的现代花粉组合以草本、灌木花粉占优势，不过特 征类群的相对丰度具有显著差别。高原荒漠带的现代花粉组合有高含量的䓠科Chenopodiaceae花粉，而草原带以 莎草科Cyperaceae占明显优势. 花粉比值能够清楚地指示青藏高原草原带和荒漠带植被和气候的差异. 蓠属/藜科 比值(Artemisia/Chenopodiaceae)和乔木/非乔木花粉比值(arboreal/non-arboreal)可指示冬季降水量的变化，蒿属/莎 草科比值(Artemisia/Cyperaceae) 以及喜旱类群总相对丰度升高指示气候变暖、变干. 按湖泊周围的植被盖度对研 究点进行聚类分析, 发现研究样点可以分为草甸、草原、荒漠草原、荒漠等4个植被组. 利用随机森林算法建立 花粉-植被重建模型, 结果显示, 随机森林模型可以准确地鉴别青藏高原的草原带和荒漠带; 当研究样点植被类型 按聚类分析结果分为4种时, 随机森林模型准确性略降低, 但仍有较可靠的预测能力. 今后将更多的湖泊表层沉积 物花粉组合数据作为随机森林算法的训练集时, 建立的花粉-植被模型极有潜力在青藏高原古植被重建中得到广 泛运用。
\end{abstract}

关键词现代花粉组合, 青藏高原, 湖泊表层沉积物, 花粉-气候关系, 花粉-植被重建模型

\section{1 引言}

孢粉学是第四纪植物学最重要的研究方向之一, 研究成果对现代生态学和生物地理学的发展有重要补 充和促进作用(Birks, 2019). 基于化石花粉序列重建过 去的植被和气候变化必须以现代花粉与植被、气候的
关系为依据. 现代花粉数据是建立花粉-气候(Birks, 1998; Jackson和Williams, 2004; Birks等, 2010)和花粉植被(Sugita, 1994, 2007a, 2007b; Gaillard等, 2008)数量 关系模型的基础.

为深入认识花粉与植被、气候之间的关系, 中国 不同地区已经开展了大量现代花粉组合研究(如Liu等, 
1999; Luo等, 2010; Zhang等, 2010; Zheng等, 2014; Xu 等, 2016). 其中, 青藏高原因对亚洲气候、环境的重要 控制作用(An等, 2001; Molnar等, 2010; An等, 2015), 成 为古生态、古环境研究的重点地区，其花粉现代过程 研究也受到了广泛关注.

青藏高原已经在不同空间尺度积累了丰富的花粉 现代过程研究，其中包括若干大空间尺度的研究. Yu 等(2001)构建了青藏高原主要花粉类群的相对丰度空 间分布格局，分析花粉组合与植被的关系; Shen等 (2006)研究高原东部现代花粉组合与气候的关系, 建 立了高原东部花粉-气候转换函数; Herzschuh及其合 作者在高原中部和东部 113 个湖泊开展了一系列现代 花粉组合研究: (1) 检验常用花粉比值指示气候变化的 可靠性(Herzschuh, 2007), (2) 评估主要花粉类群与现 代植被和气候的关系(Herzschuh和Birks, 2010), (3) 建 立青藏高原湖泊沉积物花粉与气候因子的转换函数 (Herzschuh等, 2010); Lu等(2011)综合整个青藏高原大 量现代花粉数据, 探讨花粉与气候的关系, 在此基础上 利用不同算法建立花粉-环境因素转换函数, 通过对比 获取最合适的转换函数； Li等(2020)分析了青藏高原 东部的现代花粉组合，揭示乔木花粉空间分布与亚洲 夏季风向青藏高原挺进路径和强度的关系.

除了上述大空间尺度的综合分析外，青藏高原还 有不少在局部地区开展的现代花粉研究: 如高原西北 部昆仑山(翁成郁等, 1993; Cour等, 1999), 东北部青海 湖盆地(Shang等，2009)、柴达木盆地及其周边地区 (Wei等, 2011; Zhao和Herzschuh, 2009), 中部一条经向 断面(Zhang等, 2015), 中部和西部多个湖泊(Ma等, 2017a, 2017b), 东部两个海拔断面(Zhang等, 2017), 中 南部拉萨谷地(Zhang等，2018)，南部亚东地区(Zhang 等, 2020)等.

值得注意的是，上述研究中的花粉组合大多提取 自表土或苔藓，仅有少数工作分析了湖泊表层沉积物 和空气采样花粉捕捉器的现代花粉记录. 前人研究已 经指出不同类型的沉积物中花粉信号存在差异(Wilmshurst和McGlone，2005；Zhao等，2009；Lisitsyna等， 2012; Qin等, 2015). 古生态研究中的化石花粉序列多 来自湖泊钻孔，因此湖泊表层沉积物的现代花粉组合 最适合作为解读化石花粉数据的现代参照. 目前, 青 藏高原仅有少数研究分析了湖泊表层沉积物的现代花 粉组合，包括Herzschuh及其合作者在高原中部和东部
的系列研究(Herzschuh，2007; Herzschuh等，2010; Herzschuh和Birks，2010)，Ma等(2017a，2017b)在高原 中部和西部的报道等. 青藏高原亟需开展更多的湖泊 表层沉积物现代花粉组合研究.

本研究报道了青藏高原草原带和荒漠带 34 个湖泊 的表层沉积物花粉组合, 采用数量分析方法揭示高原 草原带和荒漠带现代花粉组合的特征，分析常用花粉 指数(蒿属/藜科比值、蒿属/莎草科比值、乔木/非乔 木花粉比值等)与气候因子的关系, 评估高原现代花粉 组合与植被的关系, 并运用机器学习算法建立花粉-植 被重建模型。

\section{2 材料和方法}

\section{1 研究区概况}

青藏高原总面积约 254 万 $\mathrm{km}^{2}$ (张镱锂等, 2014), 平 均海拔在 $4000 \mathrm{~m}$ 以上. 沿东南至西北的热力和湿度梯 度，青藏高原的植被大致呈现森林-草甸-草原-荒漠的 高原地带性变化(张新时，1978，2007). 本文的湖泊样 点分布在高原北部、中部和西部(图1), 主要处于草原 带和荒漠带中.

青藏高原的草原带由针茅属(紫花针茅Stipa purpurea、长芒草S. bungeana、座花针茅S. subsessiliflora var. basiplumosa、昆仑针茅S. roborowskyii、丝颖针茅 S. capillacea等)、蒿属(藏沙蒿Artemisia wellbyi、藏南 蒿A. younghusbandii、冻原白蒿 $A$. stracheyi等)、苔草 属(青藏苔草Carex moorcroftii、窄叶苔草C. montiseverestii等)等植物占优势. 此外, 常见扇穗茅Littledalea racemose、固沙草Orinus thoroldii、白草Pennisetum flaccidum、三芒草Aristida adscensionis等禾草，以及 变色锦鸡儿Caragana versicolor、狼牙刺Sophora moorcroftiana、香柏Sabina pingii var. wilsonii、金露 梅Potentilla fruticosa等灌木(张新时, 2007).

青藏高原荒漠带常以藜科为优势植物，包括驼线 藜属(垫状驼线藜Ceratoides compacta, 驼线藜C. latens)、猪毛菜属(蒿叶猪毛菜Salsola abrotanoides)、 梭梭属(梭梭Haloxylon ammodendron)、盐爪爪属(盐 爪爪Kalidium foliatum、尖叶盐爪爪K. cuspidatum)等. 其他喜旱植物也可成为优势植物, 如膜果麻黄 Ephedra przewalskii、霸王Zygophyllum xanthoxylon、大白刺 Nitraria roborowskii，小果白刺 N. sibirica、西藏亚菊 


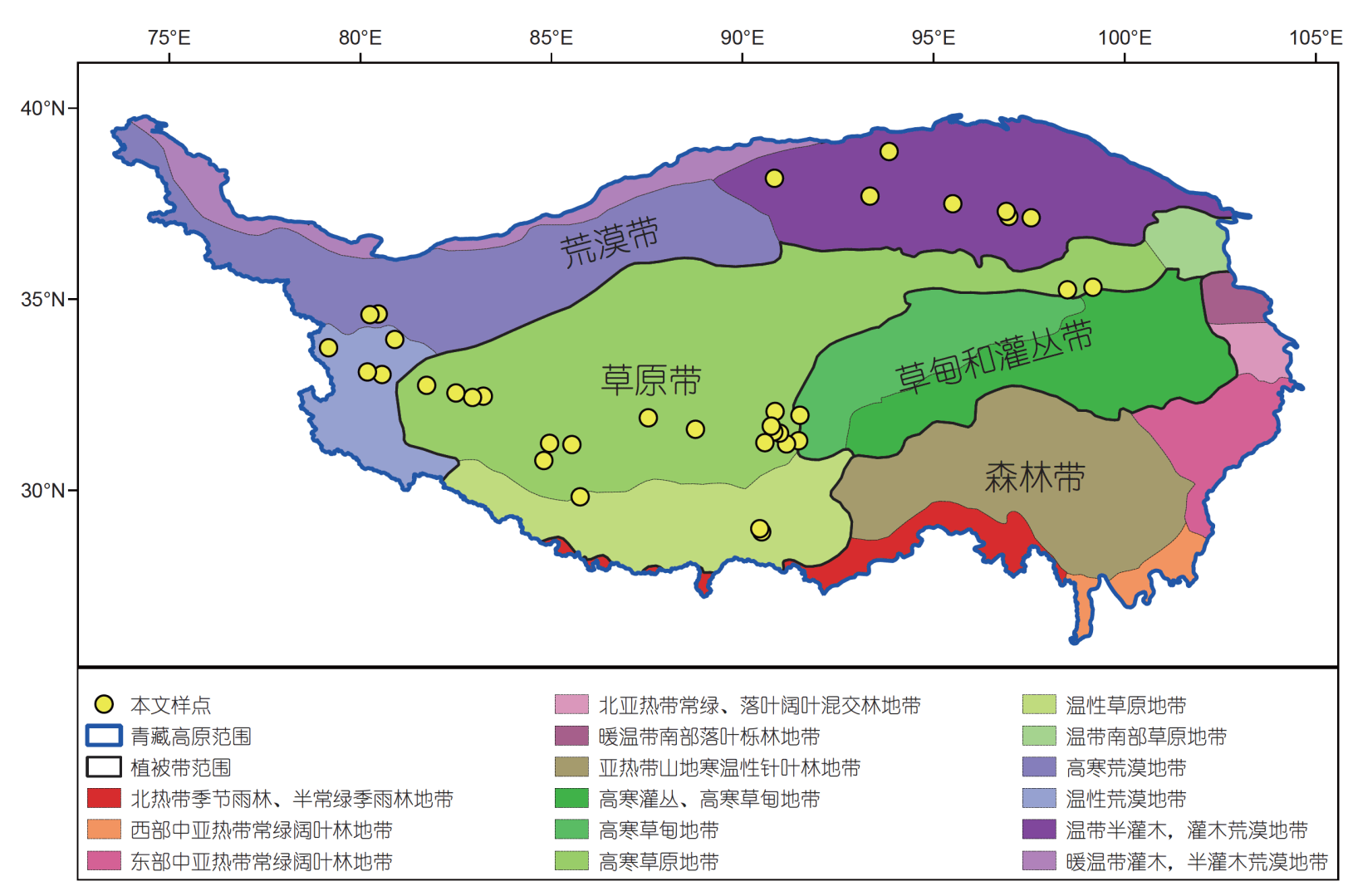

图 1 青藏高原植被带及研究样点位置

青藏高原的范围参考张镱锂等(2014), 植被带划分参考中国科学院中国植被图编辑委员会(2007)

Ajania tibetica、粉花蒿Artemisia rhodantha, 沙蒿A. arenaria等。一些禾本科(如紫花针茅、沙生针茅 $S$. glareosa)和莎草科(青藏苔草)植物与上述典型荒漠植 物可一同构成荒漠-草原植被(张新时, 2007).

\section{2 样品采集和花粉分析}

在青藏高原34个湖泊(图1，表1)的中心采集湖泊 表层沉积物(湖泊沉积物顶部1 2cm) 作为花粉分析样 品. 其中 22 个湖泊位于草原带, 12 个位于荒漠带. 草原 带中的 4 个湖泊接近草原带与草甸地带的界线, 即苦 海、冬给措那湖、错那、乃日平错等.

花粉样品经 $10 \%$ 盐酸、 $10 \%$ 氢氧化钠、 $40 \%$ 氢氟 酸及醋解溶液(acetolysis)处理(Moore等, 1991)后, 在超 声波下经 $10 \mu \mathrm{m}$ 细篎篮选, 最终提取物保存在甘油中. 化学处理前在每个样品中添加已知数量的石松狍子 (12542孢子/样品), 用以计算花粉浓度. 花粉观察和统 计在 $400 \times$ 光学显微镜下进行，花粉鉴定参考花粉形态 学专著(如席以珍和宁建长, 1994; 王伏雄等, 1995; 唐
领余等, 2016)和研究区采集、制备的标准花粉片. 每 个样品至少统计 100 粒陆生花粉, 平均每个样品统计 415 粒花粉. 样品中各花粉类群的相对丰度(百分比)基 于陆生植物花粉总数计算. 获得花粉数据后使用Tilia 1.7.16 (Grimm, 2011)绘制花粉谱. 被子植物科的分类 参照APG IV系统(The Angiosperm Phylogeny Group, 2016), 为了方便与已发表的研究作对比, 仍保留葱科 Chenopodiaceae.

\section{3 气候与植被数据}

为分析现代花粉组合与气候之间的关系, 提取了 各样点 6 个气候因子数据, 包括年均温 $\left(T_{\mathrm{ann}}\right)$ 、七月均 温 $\left(T_{\mathrm{Ju}}\right) 、$ 、月均温 $\left(T_{\mathrm{Jan}}\right) 、$ 年均降水量 $\left(P_{\mathrm{ann}}\right)$ 、七月平 均降水量 $\left(P_{\mathrm{Jul}}\right)$ 、一月平均降水量 $\left(P_{\mathrm{Jan}}\right)$ 等. 气候数据基 于我国气象站点1981 2010年30年气象记录(http:// data.cma.cn), 利用薄板样条回归(plate spline regression)插值获得.

植被数据取自中国1:100万植被图(中国科学院中 
表 1 青藏高原现代花粉研究点位置信息 ${ }^{a)}$

\begin{tabular}{|c|c|c|c|c|c|c|}
\hline 编号 & 湖泊 & 纬度 $\left({ }^{\circ} \mathrm{N}\right)$ & 经度 $\left({ }^{\circ} \mathrm{E}\right)$ & 海拔(m a. s. 1.) & 面积 $\left(\mathrm{km}^{2}\right)^{*}$ & 植被带 \\
\hline 1 & 苦海 & 35.32 & 99.17 & 4132 & 44.4 & 草原带 \\
\hline 2 & 冬给措那湖 & 35.25 & 98.5 & 4086 & 232.2 & 草原带 \\
\hline 3 & 错那 & 31.97 & 91.5 & 4590 & 182.4 & 草原带 \\
\hline 4 & 乃日平错 & 31.3 & 91.47 & 4530 & 69.6 & 草原带 \\
\hline 5 & 崩错 & 31.22 & 91.15 & 4671 & 141.3 & 草原带 \\
\hline 6 & 蓬错 & 31.5 & 90.97 & 4534 & 135.7 & 草原带 \\
\hline 7 & 兹格塘错 & 32.07 & 90.85 & 4573 & 191.4 & 草原带 \\
\hline 8 & 江错 & 31.53 & 90.82 & 4603 & 36.1 & 草原带 \\
\hline 9 & 达如错 & 31.68 & 90.75 & 4688 & 54.2 & 草原带 \\
\hline 10 & 巴木错 & 31.25 & 90.58 & 4565 & 190.9 & 草原带 \\
\hline 11 & 沉错 & 28.92 & 90.5 & 4437 & 39.1 & 草原带 \\
\hline 12 & 空姆错 & 29.48 & 90.45 & 4450 & 40.4 & 草原带 \\
\hline 13 & 错鄂 & 31.6 & 88.77 & 4568 & 269 & 草原带 \\
\hline 14 & 达则错 & 31.9 & 87.53 & 4470 & 244.7 & 草原带 \\
\hline 15 & 打加错 & 29.83 & 85.75 & 5151 & 114.5 & 草原带 \\
\hline 16 & 齐格错 & 31.2 & 85.53 & 4667 & 20.3 & 草原带 \\
\hline 17 & 达瓦错 & 31.23 & 84.95 & 4628 & 114.4 & 草原带 \\
\hline 18 & 做布错 & 30.78 & 84.8 & 4645 & 64.3 & 草原带 \\
\hline 19 & 达热布错 & 32.47 & 83.22 & 4438 & 21 & 草原带 \\
\hline 20 & 别若则错 & 32.43 & 82.93 & 4407 & 33.2 & 草原带 \\
\hline 21 & 扎仓茶卡 & 32.55 & 82.5 & 4354 & 128.25 & 草原带 \\
\hline 22 & 阿翁错 & 32.75 & 81.73 & 4430 & 58.6 & 草原带 \\
\hline 23 & 尔海 & 37.13 & 97.55 & 2852 & 32 & 荒漠带 \\
\hline 24 & 托素湖 & 37.17 & 96.97 & 2808 & 165.9 & 荒漠带 \\
\hline 25 & 可鲁克湖 & 37.3 & 96.9 & 2817 & 56.7 & 荒漠带 \\
\hline 26 & 小柴旦湖 & 37.5 & 95.5 & 3177 & 71.5 & 荒漠带 \\
\hline 27 & 苏干湖 & 38.87 & 93.83 & 2796 & 106 & 荒漠带 \\
\hline 28 & 西台吉乃尔湖 & 37.7 & 93.33 & 2688 & 126 & 荒漠带 \\
\hline 29 & 尔斯库勒湖 & 38.17 & 90.83 & 2857 & 123.8 & 荒漠带 \\
\hline 30 & 结则茶卡 & 33.95 & 80.9 & 4530 & 107.6 & 荒漠带 \\
\hline 31 & 热帮错 & 33.03 & 80.57 & 4326 & 31.6 & 荒漠带 \\
\hline 32 & 龙木错 & 34.62 & 80.47 & 5010 & 97 & 荒漠带 \\
\hline 33 & 松木希错 & 34.6 & 80.25 & 5057 & 24.6 & 荒漠带 \\
\hline 34 & 宗雄错 & 33.1 & 80.18 & 4351 & 7.2 & 荒漠带 \\
\hline
\end{tabular}

a) * 参考王苏民和窦鸿身(1998)

国植被图编辑委员会, 2007). 在栅格化的植被图中, 通 过沿湖泊样点湖岸轮廓逐步扩大的缓冲区(buffer)依次 提取各样点周围不同范围内的土地覆盖(land cover)数 据, 以 $1 \mathrm{~km}$ 为步长, 最大范围达湖岸以外 $50 \mathrm{~km} .34$ 个湖
泊周围 $50 \mathrm{~km}$ 范围内共包含 90 种土地覆盖类型(见网络 版附表 1 和附表 2 , http://earthen.scichina.com), 可归并为 9个植被类型(即针叶林、灌丛、荒漠、荒漠草原、草 原、草甸、沼泽、高山植被、栽培植被等)以及 1 个非 
植被类型(包括水体和裸地). 归并后的植被类型的盖度 (coverage)通过加和相应土地覆盖类型的盖度获得.

通常, 同种植物距离采样点越近的, 传播并沉积到 采样点的花粉就越多. 为了校正不同距离的植物对采 样点花粉组合的贡献, 需要对植被数据进行距离加权 (Gaillard等, 2008). 本文采用距离倒数方法(Prentice和 Webb, 1986)对植被数据进行加权, 不同距离的原始植 被盖度分别乘以其距湖岸的距离倒数. 距离加权的植 被盖度用于后续数量分析.

\section{4 数量分析}

利用排序技术分析不同样点花粉组合之间，以及 花粉组合与气候因子之间的关系. 降趋势对应分析 (detrended correspondence analysis, DCA)结果表明, DCA第一排序轴的长度为 1.58 个标准差单位，指示基 于线性模型的排序方法更适合分析本文数据. 因此, 采用主成分分析(principal components analysis，PCA) 对花粉数据进行排序. 排序分析时仅采用至少在一个 样品中相对丰度超过 $2 \%$ 的类群, 花粉数据在排序分析 前作了平方根转换.

大体上，花粉与植物丰度之间的相关性随采样点 周围植被调查的范围增大而升高，增大到一定范围后 相关性将不再升高(Sugita，2007b)。这个范围被Sugita (1994)定义为相关花粉源区(relevant source area of pollen, RSAP), 花粉组合能够很好地反映相关花粉源 区范围内的植被变化(Sugita等，1999). 在掌握详细的 现代花粉与植物丰度数据后, 即可利用扩展 $R$ 值模型 (extended $R$-value model)和最大似然法估算出相关花 粉源区的大小(Parsons和Prentice，1981；Sugita，1994; Bunting等, 2013). 然而, 本文研究样点缺乏包含植物丰 度或盖度的植被组成数据，无法采用上述方法估算相 关花粉源区. 因此, 本文采取了一种“妥协”的策略, 尝 试利用Mantel检验(Mantel test, Mantel, 1967; Legendre 和Fortin，1989)来评估花粉组合与植被盖度之间的相 关性. Mantel检验可用于分析两个相异矩阵之间的相 关性，利用该方法分别评估花粉数据与湖岸周围不同 范围大小的植被数据之间的关系，进而找出与花粉组 合相关性最大的植被调查范围. 原始的植被盖度和经 距离加权的植被盖度数据都与花粉数据作了对比. 花 粉和植被数据首先进行了标准化，然后计算各自的 “Bray-Curtis”相异矩阵, 再用Mantel检验分析两个相异
矩阵的相关性, Mantel检验的相关系数采用Pearson积 距相关(Pearson's product-moment correlation)计算 得出.

基于各样点周围的植被数据, 利用层次聚类分析 (hierarchical cluster analysis)对样点进行分组. 对植被 盖度数据作标准化，用“Bray-Curtis”距离衡量样点间 的差异, 采用非加权配对算术平均法(unweighted pair group method with arithmetic mean, UPGMA)进行聚类.

利用一种机器学习算法——随机森林算法(random forest, Breiman, 2001)构建花粉-植被模型, 并评估 该模型预测青藏高原不同植被类型的可靠性. 采用两 套方案划分采样点的植被类型, 一为按照样点所处的 植被带进行划分(植被带方案), 二基于样点周围植被 盖度的层次聚类结果进行划分(聚类方案).

上述数量分析都在 R version 3.5.1 (R Core Team, 2018)运行, 加载vegen 2.5-2 (Oksanen等, 2018)用于排 序分析、Mantel检验和层次聚类分析, 加载randomForest 4.6-14 (Liaw和Wiener, 2002)用于随机森林算法.

\section{3 结果}

\section{1 花粉组合}

青藏高原草原带和荒漠带34个湖泊表层沉积物样 品中共发现72个陆生植物花粉类群. 非乔木花粉占统 治地位，相对丰度平均可达 $91.36 \%$ (77.88 100\%), 其 中以蒿属Artemisia、莎草科Cyperaceae、菉科Chenopodiaceae和禾本科Poaceae花粉最为丰富. 乔木花粉平 均占 $6.93 \%$ (0 19.82\%), 其中松属Pinus 和栋属Quercus 最常见. 两个高原植被带的花粉组合具有明显差异 (图2).

（i ) 草原带. 青藏高原草原带现代花粉组合中蒿 属(1.47 62.95\%)和莎草科(2.27 69.85\%)占优势. 禾本 科也有较高含量，相对丰度为 $2.27 \sim 18.81 \%$ 。藜科 $(0.46 \sim 16.36 \%)$ 、紫苑型Aster-type (0 4.59\%)、毛茛科 Ranunculaceae (0.45 6.36\%)、唐松草属Thalictrum $(0 \sim 3.38 \%)$ 和菩薇科Rosaceae $(0 \sim 1.92 \%)$ 花粉较为常见. 春黄菊型Anthemis-type $(0 \sim 19.09 \%)$ 、景天科Crassulaceae $(0 \sim 14.22 \%)$ 和水柏枝属Myricaria (0 7.19\%)通常 含量极低, 仅在个别样品中出现高含量. 乔木花粉中主 要包括松属 $(0.18 \sim 13.64 \%)$ 、栎属 $(0 \sim 5.93 \%)$ 、桤木属 Alnus (0 3.69\%)、华木属Betula (0 3.69\%)和云杉属 


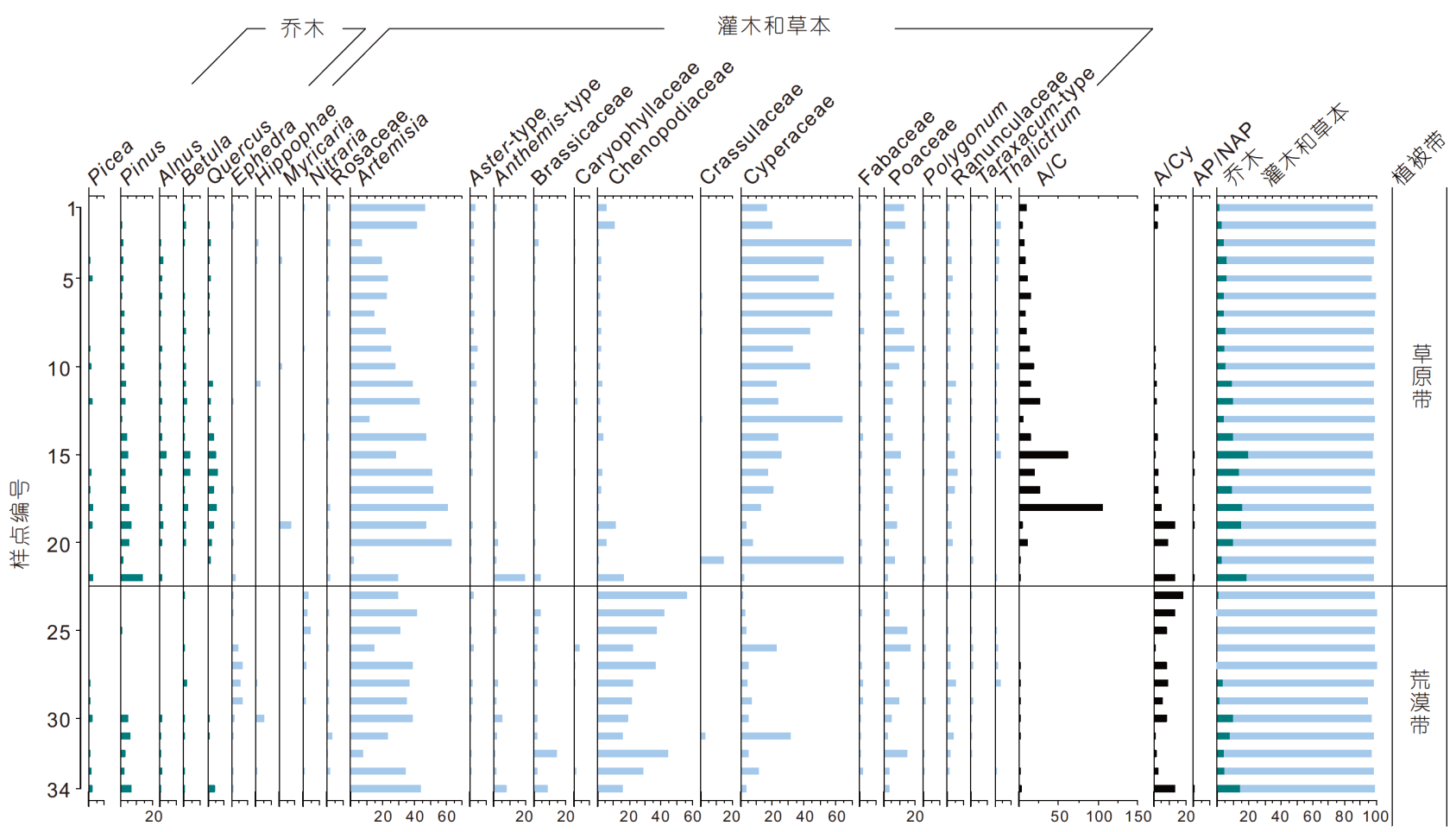

图 2 青藏高原草原带和荒漠带现代花粉谱

Picea $(0 \sim 2.73 \%)$.

（ii）荒漠带. 青藏高原荒漠带现代花粉组合中藜 科(15.71 56.19\%)和蒿属(7.71 44\%)花粉占优势. 莎草 科花粉相对丰度明显低于草原带样品(1.61 31.41\%), 仅在两个样品中有较高含量，小柴旦湖为 $22.22 \%$, 热 帮错含 $31.41 \%$. 禾本科占 $2.09 \%$ 至 $16.19 \%$. 十字花科 Brassicaceae (0 14.00\%)和春黄菊型(0 7.33\%)花粉较 常见. 喜旱类群比草原带样品含量高, 如麻黄属Ephedra (0 6.61\%)、白刺属Nitraria (0 4.14\%)等. 荒漠带 样品中乔木花粉相对丰度比草原带低( 0 14.67\%)，其 中同样以松属(0 6.67\%)和栎属(0 4\%)最多.

\section{2 主成分分析结果}

主成分分析显示，PCA第一排序轴(第一轴)解释 了花粉组合数据中 $47.79 \%$ 的变化，第二排序轴(第二 轴)能解释 $18.28 \%$ (图3). 荒漠带样点几乎都分布在第 一轴负方向. 草原带样点大多分布在第一轴正方向, 少 数样点处于第一轴的负方向. 从第二轴看, 荒漠带样点 除两个分布在正方向外, 其余均处于负方向; 草原带样 点则散布于第二轴上下两部分.
从花粉类群来看, 藜科、莎草科和蒿属最为重要. 禾本科和莎草科作为青藏高原草原带的优势植物，处 于PCA双序图的右下侧. 喜旱植物藜科、麻黄属和白 刺属处于PCA图的左下侧. 所有乔木类群都位于第二 轴的正方向，包括松属、栎属、桦木属、云杉属、桤 木属等.

气候因子中, $P_{\mathrm{ann}}$ 和 $P_{\mathrm{Jul}}$ 与 $\mathrm{PCA}$ 第一轴有正相关关 系, $T_{\mathrm{ann}}$ 和 $T_{\mathrm{Jul}}$ 与第一轴有负相关. 荒漠带样点对应较高 的年均温和七月均温, 草原带样点与较高的年均降水 量和七月平均降水量相关.

\subsection{Mantel检验结果}

青藏高原湖泊表层沉积物现代花粉组合与距离加 权植被数据的Mantel检验显示，随植被调查范围扩大， 花粉组合与植被盖度之间的相关性升高, 并在调查范 围达到湖岸以外 $9 \mathrm{~km}$ 时相关性最高, 之后逐渐降低(图 4). 花粉组合与原始植被数据的Mantel检验结果表明, 在植被调查范围扩大到湖岸以外 $3 \mathrm{~km}$ 时，二者相关性 迅速升至最高，然后急剧下降(图4). 花粉组合与距离 加权植被数据之间相关性更高. 因此，后续分析花粉- 

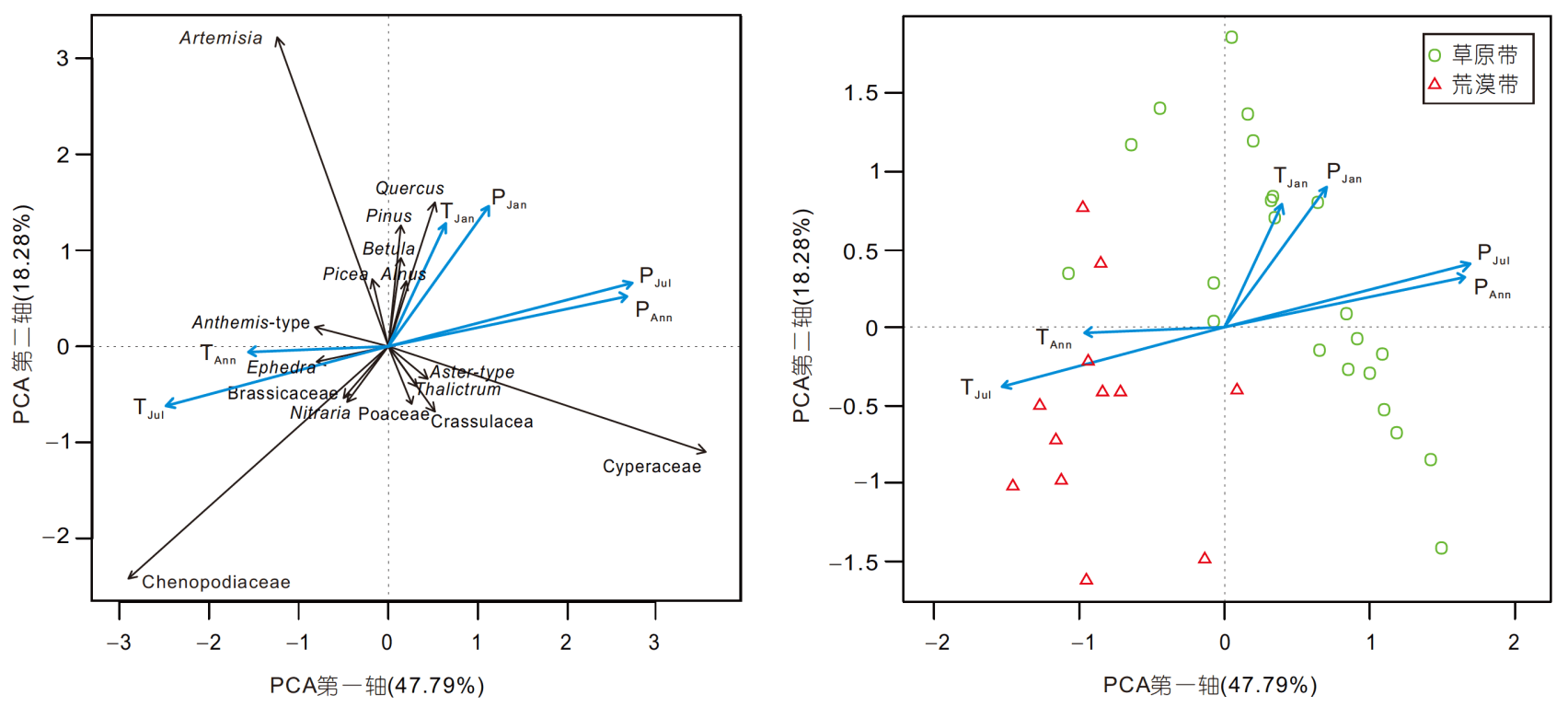

图 3 青藏高原湖泊表层沉积物花粉组合的主成分分析结果图

植被关系时均采用距离加权的植被盖度数据, 并且湖 岸以外 $9 \mathrm{~km}$ 范围的植被数据最适合反映花粉组合与植 被的关系.

\section{4 层次聚类分析结果}

基于湖岸以外 $9 \mathrm{~km}$ 范围内的距离加权植被盖度 数据进行层次聚类分析, 结果表明湖泊样点可分为 4 组(图5). 这4个组反映了研究样点周围植被盖度的差 异(见网络版附图1). 组1包含7个样点, 周围植被主要 是荒漠; 组 2 仅含两个样点, 植被以草甸占优势; 组 3 有 16 个样点, 周围植被以草原为主; 组 4 含 5 个样点, 周围 植被主要是荒漠草原. 据此, 可将本研究 34 个湖泊的 植被按聚类结果分别划分为荒漠、草甸、草原和荒 漠草原 4 个植被组, 该划分方案用于后续随机森林 算法.

\section{5 随机森林算法结果}

当样点植被类型按照其所处植被带进行划分时 (植被带方案), 随机森林模型中决策树数量设为 100 , 每个节点随机选取的变量数设为 20 . 模型训练结果显 示, 袋外误差(out-of-bag error)仅为 2.94\%, 预测准确率 极高. 除一个草原带样点被判定为荒漠外, 其余样点均 能正确归类(表2). 图6展示了花粉类群对植被带划分 准确性的重要程度. 藜科对模型准确率的重要性明显

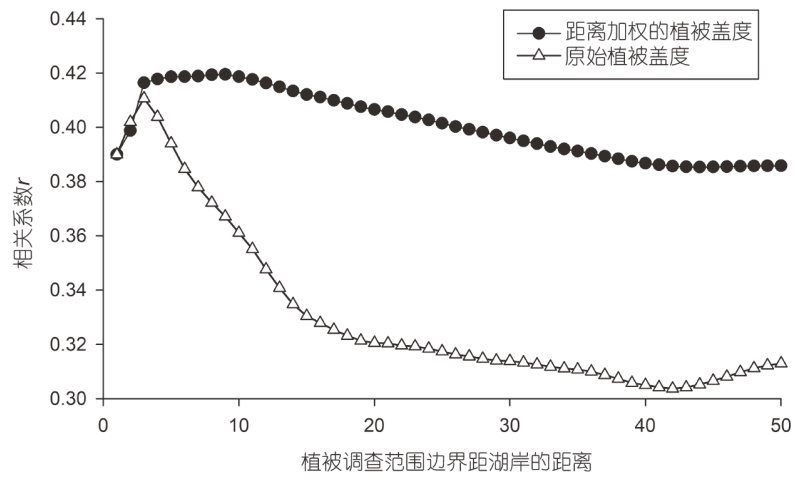

图 4 Mantel检验显示的花粉组合与植被之间的相关性

高于其他类群, 平均准确率降低程度 (mean decrease in accuracy)为 19.39, 在区分草原带和荒漠带时起关键 作用.

当样点植被类型按照聚类分析的 4 个植被组进行 划分时, 随机森林模型中决策树数量设为 400 , 每个节 点随机选取的变量数设为 5 . 模型袋外误差为 $23.53 \%$, 预测准确率低于上述植被带模型. 所有草原样点均能 正确识别; 两个草甸样点均都被误判为草原, 11 个荒 漠样点中的两个被识别为荒漠草原, 荒漠草原样点被 重建为 3 种不同的植被: 2 个荒漠、1 1 个荒漠草原、2个 草原(表3). 藜科同样是区分 4 个植被组最重要的类群, 其平均准确率降低程度(mean decrease in accuracy)为 11.96 (图6). 麻黄属(平均准确率降低程度为 8.99 , 下同) 


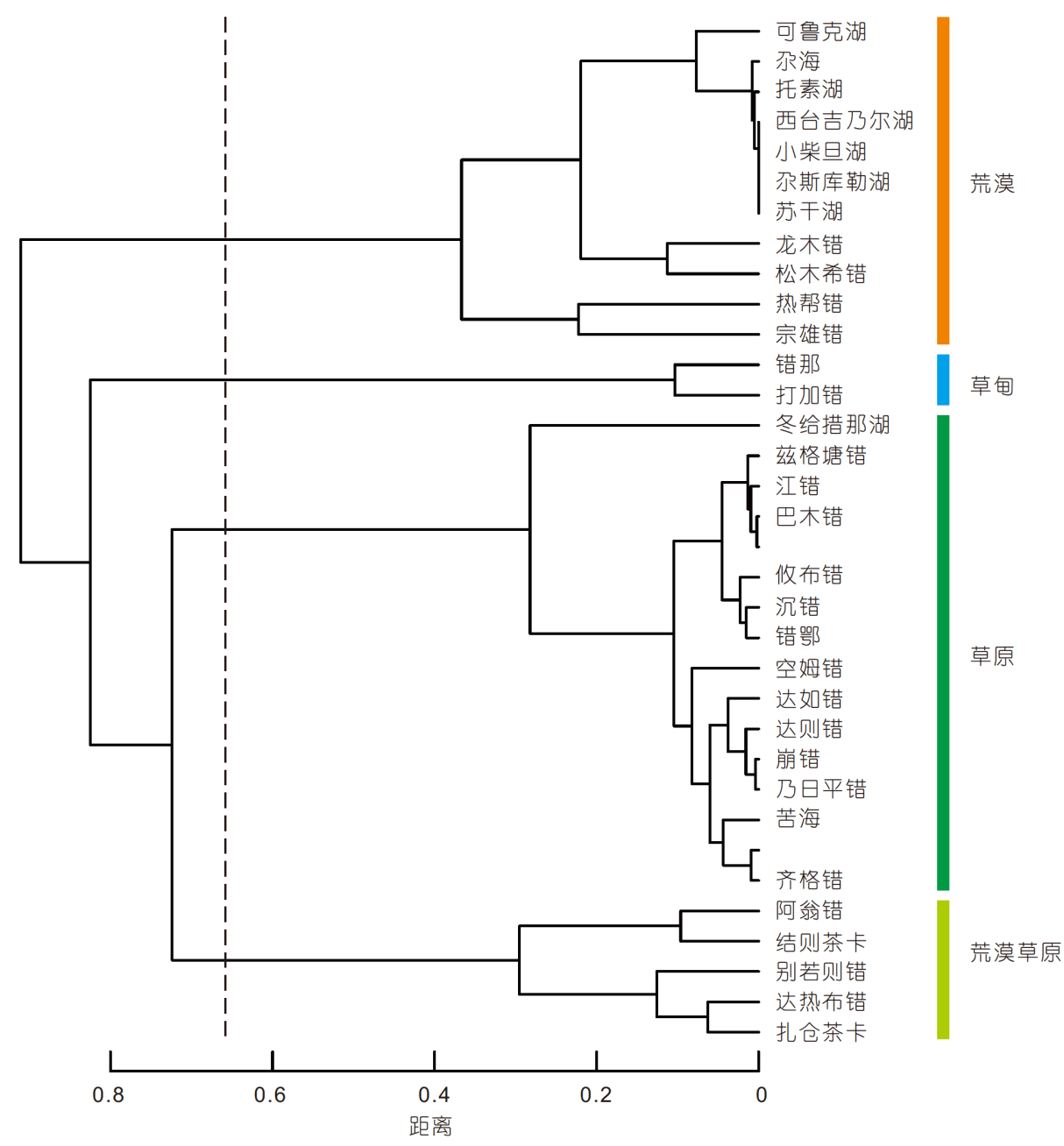

图 5 基于湖岸以外 $9 \mathrm{~km}$ 范围内距离加权植被数据的层次聚类树状图

表 2 基于现代花粉组合识别青藏高原草原带和荒漠带的随机森林模型误差矩阵

\begin{tabular}{ccccc}
\hline \multirow{2}{*}{$\begin{array}{c}\text { 实际与预测植被带对比 } \\
\text { (模型袋外误差2.94\%) }\end{array}$} & \multicolumn{3}{c}{ 预测植被带 } & 误差 \\
\cline { 3 - 4 } & 草原带 & 草原带 & 1 & 0.045 \\
实际植被带 & 荒漠带 & 21 & 12 & 0 \\
\hline
\end{tabular}

和莎草科(8.51)具有很高的重要性。此外，春黄菊型 (6.97)、桤木属(6.14)和松属(5.31)也对模型准率性有 重要影响.

\section{4 讨论}

\section{1 青藏高原草原带和荒漠带现代花粉组合}

青藏高原草原带和荒漠带湖泊表层沉积物中现代
花粉组合都以草本和灌木花粉占优势，体现了开阔景 观的特征. 两个植被带的现代花粉组合有不少相似之 处: 例如, 蒿属花粉相对丰度都较高, 通常都有一定数 量的禾本科花粉，菩薇科、毛莨科、唐松草属、蓼属 Polygonum等类群在两个植被带的现代花粉组合中含 量类似.

两个植被带的现代花粉组合有显著差别．荒漠带 现代花粉组合中藜科花粉相对丰度明显高于草原带, 

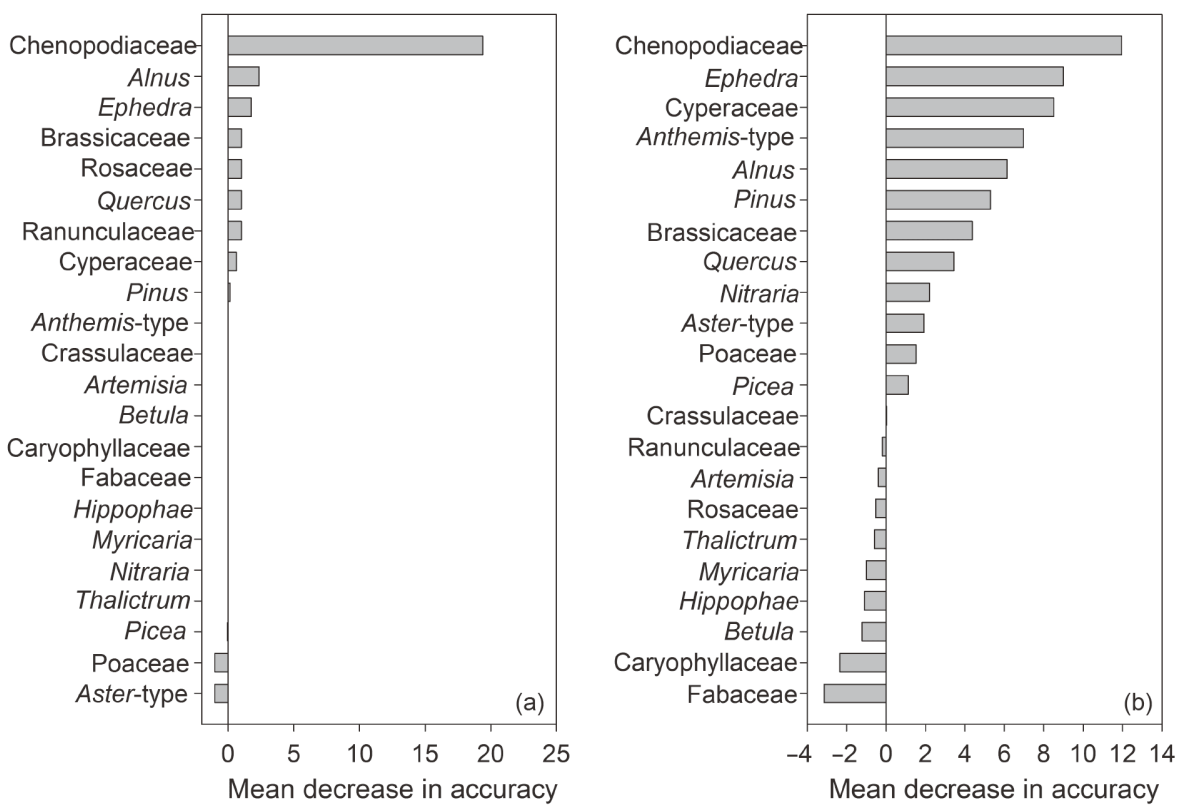

图 6 基于花粉组合识别不同植被带(a)和植被组(b)的随机森林模型中以平均准确率降低程度(mean decrease in accuracy)衡 量的花粉类群重要性

表 3 基于现代花粉组合识别青藏高原不同植被组的随机森林模型误差矩阵

\begin{tabular}{|c|c|c|c|c|c|c|}
\hline \multirow{2}{*}{\multicolumn{2}{|c|}{$\begin{array}{l}\text { 实际与预测植被组对比 } \\
\text { (模型袋外误差 } 23.53 \%)\end{array}$}} & \multicolumn{4}{|c|}{ 预测植被组 } & \multirow{2}{*}{ 误差 } \\
\hline & & 草甸 & 草原 & 荒漠草原 & 荒漠 & \\
\hline \multirow{4}{*}{ 实际植被组 } & 草甸 & 0 & 2 & 0 & 0 & 1 \\
\hline & 草原 & 0 & 16 & 0 & 0 & 0 \\
\hline & 荒漠草原 & 0 & 2 & 1 & 2 & 0.80 \\
\hline & 荒漠 & 0 & 0 & 2 & 9 & 0.18 \\
\hline
\end{tabular}

麻黄属、白刺属等喜旱类群的花粉相对丰度也较草原 带高，其母体植物都是青藏高原荒漠植被中常见的耐 旱植物。草原带现代花粉组合中，莎草科成了优势类 群，阔叶乔木的花粉相对丰度比荒漠带高，包括栎 属、桦木属、桤木属等.

青藏高原草原带和荒漠带湖泊表层沉积物中现代 花粉组合的差异在已发表的研究中也有报道(采样点 位置见网络版附图2). 所有对高原荒漠植被湖泊表层 沉积物中现代花粉组合的研究都发现愁科花粉占优 势，并且蒿属花粉相对丰度较高(本文; Herzschuh， 2007; Ma等, 2017a; Ma等, 2017b). 然而, 高原草原植 被湖泊表层沉积物的现代花粉组合中，愁科花粉相对 丰度都在 $20 \%$ 以下．莎草科、蒿属和禾本科成了优势 类群，不过在草原带不同区域，这三个类群的相对丰
度也有差异. Herzschuh(2007)报道的草原样点分布在 高原草原带的东部(网络版附图2), 研究结果显示莎草 科比禾本科和蒿属花粉相对丰度更高. 草原带西部(本 文; Ma等，2017a)的现代花粉组合中蒿属花粉占优势， 莎草科和禾本科花粉含量都低于东部样点. 这个现象 可能体现了青藏高原沿东南至西北干旱度逐渐加强的 变化(吴绍洪等, 2005), 干旱度的差异可能导致草原带 东部莎草科植物较丰富, 相反西部以蒿属较繁盛.

青藏高原草原带与中国北方温带草原区的湖泊表 层沉积物现代花粉组合有相似之处, 也有明显区别. 温 带草原区同样以蒿属为优势花粉类群，禾本科花粉通 常也占一定比例(Zhao等，2009; Han等，2017). 不过， 莎草科和藜科花粉的相对丰度在两个草原区域存在显 著差异. 莎草科花粉在青藏高原草原带占优势, 但是在 
北方温带草原区很少出现高含量. 青藏高原草原带现 代花粉组合中高含量的莎草科花粉可能来源于湖泊周 围以莎草科植物(主要是苔草属Carex)为主要成分的 高寒草原群落, 或者零星分布的以莎草科(主要是嵩草 属Kobresia) 为优势植物的高山草甸群落. 藜科花粉的 情况相反, 在青藏高原草原带湖泊表层沉积物的现代 花粉组合中仅有较低含量，在北方温带草原区却是主 要花粉类群(Zhao等, 2009; Han等, 2017). 前人研究显 示，北方温带草原区表土花粉组合中高含量的愁科花 粉与较强的人类活动有关(Liu等，2006; Zhang等, 2010). 相对于北方温带草原区，青藏高原上较弱的人 类活动可能是其草原带湖泊表层沉积物中僽科花粉含 量不高的原因之一.

青藏高原荒漠带与中国西北暖温带、温带荒漠区 的湖泊表层沉积物现代花粉组合极为相似. 僽科和蒿 属花粉在西北荒漠区现代花粉组合中同样占优势，并 且也常见麻黄属、白刺属等喜旱植物花粉 (Zhao等, 2009; Qin等, 2015). 可见, 中国不同的荒漠区域虽然存 在地理环境差异, 但是湖泊表层沉积物的现代花粉组 合中优势类群和特征类群有很高的一致性.

总之, 青藏高原草原带的湖泊表层沉积物现代花 粉组合明显不同于荒漠带.

\section{2 常用花粉比值对植被和气候的指示意义}

主成分分析显示年均降水量、七月平均降水量、 七月均温是影响青藏高原现代花粉组合最主要的控制 因子(图3). 主成分分析第一轴能解释近半花粉数据的 变化, 而上述三个气候因子与第一轴的相关性最高. 前 人研究同样发现年均降水量对青藏高原现代花粉组合 有重要影响(如Shen等，2006; Herzschuh等，2010; Herzschuh和Birks, 2010). 青藏高原草原带样品对应了 较高的年均降水量和七月平均降水量, 以及较低的七 月均温, 即较凉湿的气候; 荒漠带样品与之相反, 对应 较高的七月均温, 和较低的年均降水量和七月平均降 水量, 即较暖干的气候. 因此, 现代花粉组合能反映青 藏高原两个植被带的气候差异.

花粉比值是有效的定性或半定量植被、气候代用 指标，常用于青藏高原的有蒿属/藜科比值(Artemisial Chenopodiaceae, A/C)、乔木/非乔木比值(arboreal/ non-arboreal, AP/NAP)、蒿属/莎草科比值(Artemisial Cyperaceae, A/Cy)等.
蒿属/䔉科比值 $(\mathrm{A} / \mathrm{C})$ 常用作干旱、半干旱区的湿 润度指标(El-Moslimany, 1990; Zhao等, 2012). 相关分 析结果(表4)显示, $\mathrm{A} / \mathrm{C}$ 与 1 月平均降水量有显著正相关 关系 $\left(r^{2}=0.50\right)$, 其原因可能在于更高的冬季降水带来 更厚的冬季雪深, 从而使生长季土壤湿度和养分有效 性更高(Peng等, 2010). A $/ \mathrm{C}$ 与年均降水量 $\left(r^{2}=0.08\right)$ 和 七月平均降水量 $\left(r^{2}=0.07\right)$ 相关性较低. Herzschuh (2007)对青藏高原东部和中部湖泊表层沉积物花粉组 合的研究指出 $\mathrm{A} / \mathrm{C}$ 与年均降水量显著相关 $\left(r^{2}=0.25\right)$. $\mathrm{Ma}$ 等(2017b)在高原西部和中部的研究也发现蒿属/藜 科比 $\mathrm{A} / \mathrm{C}$ 与年均降水量相关性较高 $\left(r^{2}=0.56\right)$. 不过, $\mathrm{Ma}$ 等(2017a)在高原西南部的研究显示 $\mathrm{A} / \mathrm{C}$ 与年均降水量 相关性不高 $\left(r^{2}=0.21\right)$. 因此, $\mathrm{A} / \mathrm{C}$ 可能可以用于反映青 藏高原冬季降水量的变化, 但是对年均降水量的指示 性还需进一步的验证.

青藏高原草原带现代花粉组合中 $\mathrm{A} / \mathrm{C}$ (平均17.79) 明显高于荒漠带(平均1.24), 个别样点存在例外的情况 (图7). 这一现象与前人的研究一致. Herzschuh(2007) 在高原东部和中部研究发现从荒漠到草原湖泊表层沉 积物的现代花粉组合中 $\mathrm{A} / \mathrm{C}$ 升高. Ma等(2017b)在高原 西部和中部地区的研究指出 $\mathrm{A} / \mathrm{C}$ 为 1.2 是区分草原和荒 漠的阈值. 总之, 在青藏高原 $\mathrm{A} / \mathrm{C}$ 能有效地识别草原和 荒漠.

乔木/非乔木比值(AP/NAP) 常用于指示研究点周 围的开阔度. 本研究的所有研究点均为开阔景观, 从植 被图上看, 离研究点最近的森林至少在 $20 \mathrm{~km}$ 以外(可 鲁克湖). 因此, 花粉组合中的乔木花粉应该都是远距 离传播而来的. 不少研究已经讨论了青藏高原上低海 拔地区的乔木花粉向高海拔传播的现象 (Cour等, 1999; Herzschuh和Birks, 2010, Zhang等, 2017). 也有一 些研究发现了用乔木花粉指示青藏高原植被和气候变 化的潜力. 例如, Herzschuh(2007)认为乔木花粉的总含 量可用于指示区域降水量变化. Lu等(2008)提出通过 云杉属和冷杉属Abies花粉相对丰度识别青藏高原树 线的阈值. Li等(2020)发现青藏高原乔木花粉相对丰度 的空间分布与亚洲夏季风向青藏高原挺进的路径密切 相关.

本研究的花粉组合中乔木花粉相对丰度在 $0 \sim 19.82 \%$, 平均为 $6.93 \%, \mathrm{AP} / \mathrm{NAP}$ 较低( $(0 \sim 0.25)$. 草原 带样点AP/NAP平均值高于荒漠样点(图7), 这可能是 由两个植被带与高原东南部森林之间的距离差异造成 
表 4 花粉比值与气候因子相关分析的决定系数 $\left(r^{2}\right)^{\mathrm{a})}$

\begin{tabular}{|c|c|c|c|c|c|c|}
\hline & 一月平均降水量 & 七月平均降水量 & 年均降水量 & 一月均温 & 七月均温 & 年均温 \\
\hline \multirow{2}{*}{$\mathrm{A} / \mathrm{C}$} & $0.50 * * *$ & 0.07 & 0.08 & $0.19 * * *$ & 0.03 & 0.005 \\
\hline & + & + & + & + & - & + \\
\hline \multirow{2}{*}{$\mathrm{A} / \mathrm{Cy}$} & 0.08 & $0.36^{* * *}$ & $0.37 * * *$ & 0.0001 & $0.43 * * *$ & $0.23 * *$ \\
\hline & - & - & - & - & + & + \\
\hline \multirow{2}{*}{ AP/NAP } & $0.26 * *$ & 0.001 & 0.0002 & 0.09 & 0.02 & 0.004 \\
\hline & + & + & + & + & - & - \\
\hline \multirow{2}{*}{ Sum $_{\text {xero }}$} & $0.26 * *$ & $0.45 * * *$ & $0.41 * * *$ & 0.001 & $0.63 * * *$ & $0.40 * * *$ \\
\hline & - & - & - & - & + & + \\
\hline
\end{tabular}

a) $* p<0.05, * * p<0.01, * * * p<0.001,+$ 正相关, - 负相关

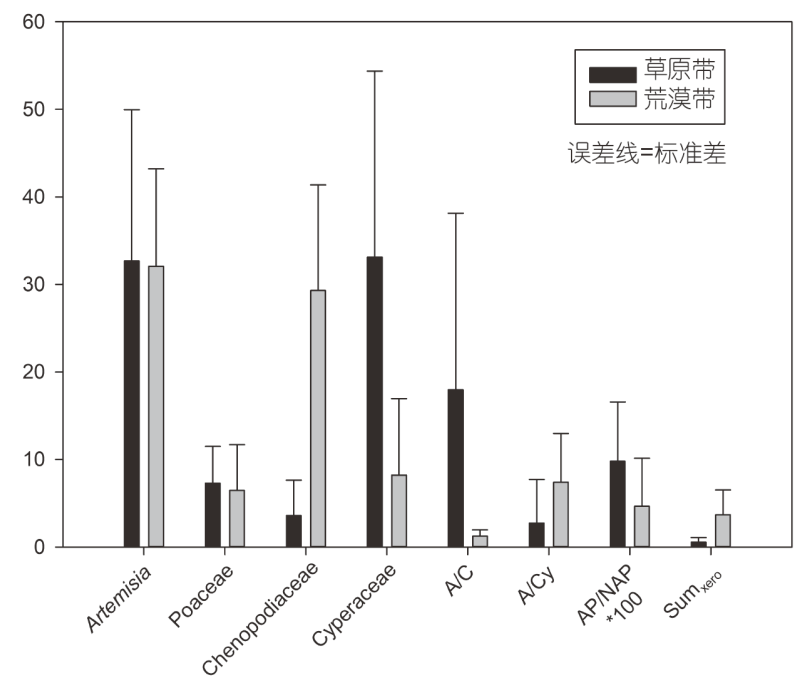

图 7 青藏高原草原带和荒漠带优势花粉类群相对丰度和 花粉比值

的(图1). 不过，高原西部一些荒漠样点(结则茶卡、热 帮错、龙木措、松木希错、宗雄错等)的AP/NAP也可 能比草原样点更高. Cour等(1999)发现在高原西部植 物覆盖度低的区域, 现代花粉组合中AP/NAP可以很 高，原因在于当地植物稀少，沉积下来的当地花粉很 少, 远距离传播的花粉占较高的比例. 上述AP/NAP较 高的荒漠带样点可能也存在这样的现象. 另外, 相关分 析显示AP/NAP与一月平均降水量之间有正相关关系 $\left(r^{2}=0.26\right)$, 反映比值可作为冬季降水量的代用指标.

蒿属/莎草科比值(A/Cy)由Herzschuh等(2006)基于 这两个类群的花粉在青藏高原东部的分布特征提出, 用作夏季温度的代用指标. 随后, Herzschuh(2007)基于 高原东部和中部湖泊表层沉积物现代花粉组合研究,
观察到大多数高寒草甸样品中 $\mathrm{A} / \mathrm{Cy}<1$, 而在温带草原 和荒漠样品中该比值 $>1$, 而且发现 $\mathrm{A} / \mathrm{Cy}$ 与七月均温显 著相关, 与年均降水量有较弱的相关性. Zhao和 Herzschuh(2009)在青藏高原东北部柴达木盆地的研究 显示草甸样点的 $\mathrm{A} / \mathrm{Cy}$ 远低于草原、荒漠草原和荒漠 样点, 该比值与七月均温有正相关关系, 与年均降水量 有负相关关系. Ma等(2017a)在高原中部和西部的研究 表明从高寒草甸和高寒草原交错带、到亚高山灌从草 原、到高寒草原、再到高寒荒漠， $\mathrm{A} / \mathrm{Cy}$ 逐渐升高，并 且与年均降水量有较强的相关性.

本研究结果显示, 青藏高原草原带 $\mathrm{A} / \mathrm{Cy}$ 大体上低 于荒漠带(图7), 可作为区分这两个植被带的指标. $\mathrm{A} / \mathrm{Cy}$ 与年均降水量 $\left(r^{2}=0.37\right)$ 和七月平均降水量 $\left(r^{2}=0.36\right)$ 之间呈负相关关系, 与年均温 $\left(r^{2}=0.23\right)$ 和七月 均温 $\left(r^{2}=0.43\right)$ 呈正相关，表明 $\mathrm{A} / \mathrm{Cy}$ 升高可以指示环境 变暖干.

青藏高原荒漠带中喜旱类群花粉各自的相对丰度 不超过 $7 \%$ (图2), 却是荒漠带的特征花粉类群, 包括麻 黄属、白刺属、柽柳属Tamarix和静㢣科Zygophyllaceae. 这些喜旱类群的总相对丰度 $\left(\mathrm{Sum}_{\mathrm{xerr}}\right)$ 在荒漠带现 代花粉组合中(平均 $3.69 \%$ )远高于草原带(平均 $0.55 \%$ )

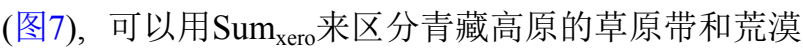
带. 另外, Sum Sero $_{\text {与 七月均温 }}\left(r^{2}=0.63\right)$ 和年均温 $\left(r^{2}=0.40\right)$ 之间有较强的正相关, 与年均降水量 $\left(r^{2}=0.41\right)$ 和七月平均降水量 $\left(r^{2}=0.45\right)$ 之间呈负相关(表 4$)$. 较高

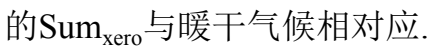

综上所述， $\mathrm{A} / \mathrm{C} 、 \mathrm{~A} / \mathrm{Cy}$ 和 $\mathrm{Sum}_{\mathrm{xero}}$ 可作为区分青藏 高原草原带和荒漠带的指标， $\mathrm{A} / \mathrm{C}$ 和AP/NAP可用于指 示冬季降水量变化, $\mathrm{A} / \mathrm{Cy}$ 和 $\mathrm{Sum}_{\mathrm{xero}}$ 升高可指示暖干条 
件加强.

\section{3 花粉-植被关系}

\subsection{1 现代花粉组合与植被的关系}

花粉分析样点的植被类型通常根据样点周围的野 外植被调查来确定. 但是, 湖泊沉积物样品对应的植被 类型难以按照这一方法准确判定，因为在野外调查整 个湖泊周围的植被是比较困难的. 因此, 通常情况下 湖泊沉积物样品对应的植被类型根据湖泊所处的植被 带或植被区来划分. 考虑到湖泊周围可以同时分布着 不同类型的植被，这样划分方案容易忽视植被的细节 信息.

从1:100万植被图看, 本研究的湖泊样点在湖岸以 外 $1 \mathrm{~km}$ 范围内最多可以同时出现6种不同的植被群系. 将这些植被信息纳入分析, 可以更深入地认识花粉与 植被的关系. 例如，宗雄错和结则茶卡两个荒漠带湖 泊的现代花粉组合中蒿属/㳟科比值远高于其他荒漠 带样点, 通过分析其湖岸以外的植被群系, 发现这两个 花粉组合中较高的蒿属花粉应该来自于两个湖泊周围 分布的大量荒漠草原和草原(见网络版附图1). 与之相 反，处于草原带的阿翁错现代花粉组合中有类似于荒 漠带样点的高含量藜科花粉，这些愁科花粉应来自于 该湖泊周围广泛分布的荒漠草原.

确定花粉样品对应的植被类型时还有另一个难 题. 当植被调查范围扩大时, 不同植被类型所占比例也 随之变化. 本研究提取植被数据的范围增大时, 涵盖的 植被群系种类增加，而且盖度最大的群系(优势群系) 也会随之改变. 例如，托素湖湖岸以外 $1 \mathrm{~km}$ 范围内有 6 种植被群系, 当扩大到湖岸以外 $10 \mathrm{~km}$ 范围时群系数量 增加到 11 种, 并且盖度最大的群系由西伯利亚白刺 (Nitraria sibirica) 荒漠转变为梭梭 (Haloxylon ammodendron)荒漠.

本研究采用Mantel检验评估花粉组合与植被盖度 之间的关系，进而确定合适的植被调查范围. 结果显 示，青藏高原湖泊表层沉积物现代花粉组合与湖岸以 外 $9 \mathrm{~km}$ 范围内的植被盖度之间相关性最高, 因此采用 这一范围内的植被数据研究花粉-植被关系. 需要说明 的是，该范围不同于Sugita(1994)提出的相关花粉源区 概念, 因为相关花粉源区反映的是花粉与母体植物丰 度的关系. 不过, 当植被中详细的植物丰度信息无法 获取时, 就无法估算出相关花粉源区, 此时, 可以通过
分析花粉组合与植被之间相关性，确定提取植被数据 的合适范围, 作为相关花粉源区的替代方案. 最终, 本 研究中各湖泊样点根据其湖岸以外 $9 \mathrm{~km}$ 范围内的植被 盖度指定植被类型.

聚类分析显示基于湖岸以外 $9 \mathrm{~km}$ 范围的植被盖度 信息, 可将所有研究样点分为 4 个组. 各组内不同样点 可能分布在不同的高原植被带，但湖岸周围都以同一 植被类型占优势(网络版附图1).4个聚类分组各对应 一种植被类型. 据此，将样点的植被类型按照聚类分 组分别定为荒漠、荒漠草原、草原和草甸中的一种.

聚类分析 4 个组的花粉组合也表现出明显差异(图 8). 草甸组样点中莎草科花粉的平均相对丰度最高, 藜 科最低; 荒漠组与之相反, 藜科花粉平均相对丰度最 高, 莎草科最低; 荒漠草原组莍科相对丰度高于草原 组, 莎草科低于草原组. A/C 从草甸组、草原组、荒漠 草原组到荒漠组逐渐降低, 反映4种植被类型的环境干 湿度差异. 荒漠草原和荒漠组的 $\mathrm{A} / \mathrm{Cy}$ 比草甸组和草原 组更高, 荒漠组Sum xero 明显高于其他三组.

\subsection{2 花粉-植被重建模型}

Sobol和Finkelstein(2018)用不同的算法建立非洲 和阿拉伯地区的花粉-植被重建模型, 发现随机森林算 法建立的模型是各模型中准确率和可靠性最高的. 随 后，Sobol等(2019)利用随机森林算法建立非洲南部的 花粉-植被重建模型，并用于Wonderkrater化石花粉序 列, 重建了当地古植被演替. 本研究在青藏高原地区 尝试利用随机森林算法建立高寒植被的花粉-植被重 建模型.

在植被带层面，随机森林模型表现出极高的准确 率(表2). 34 个样点中仅有一个样点预测错误. 随机森 林模型将处于青藏高原草原带的阿翁错重建为荒漠, 误差可能源自阿翁错周围大量荒漠群系的花粉信号 (网络版附图 1).

样点植被类型按聚类分析的 4 个植被组进行划分 时, 随机森林模型准确率低于植被带模型(表3). 草原 组样点均正确重建为草原. 荒漠组中有两个样点被误 判为荒漠草原, 可能的原因是荒漠与荒漠草原中有不 少共有植物类群(张新时, 2007). 例如, 沙生针茅(Stipa glareosa)荒漠草原群系可含有大量驼线藜Ceratoides latens、灌木亚菊Ajania fruticulosa等喜旱植物，这些 喜旱植物又是很多荒漠群系的优势植物. 同样的原因 


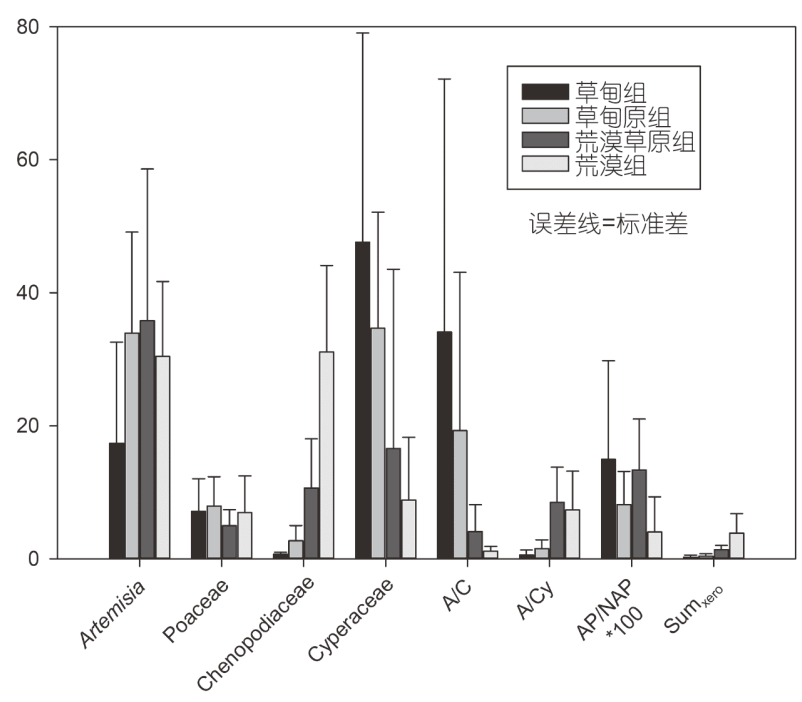

图 8 按聚类分析划分的 4 个植被组中优势花粉类群相对丰 度和花粉比值

使荒漠草原的现代花粉组合可兼具荒漠和草原植被的 花粉信号，导致荒漠草原组样点的模型预测结果最为 混乱，被识别为荒漠、荒漠草原或草原. 草甸组样点 全部被重建为草原，可能的原因有：(1) 草甸的优势植 物是莎草科, 其花粉在草甸组和草原组样点中的相对 丰度接近(图2); (2) 草原组部分样点周围的植被中包 含不少草甸群系(网络版附图1), 为草原组样点引入草 甸花粉信号; (3) 草甸组仅有两个样点, 在随机森林算 法中代表性不足.

本研究用作随机森林算法训练集的花粉组合数量 还较少, 尤其是将样点按聚类结果分为 4 组以后, 各组 样本量更低. 今后的研究如能将更多青藏高原湖泊表 层沉积物花粉组合做为训练集, 无疑将提高随机森林 模型的可靠性.

随机森林算法的结果显示, 藜科在植被带模型中 起关键作用，其他类群对模型准确率的贡献远不如藜 科(图6)，表明愁科花粉对区分青藏高原草原带和荒漠 带极为重要. 愁科在植被组模型中同样最为重要, 不过 其他类群的重要性比植被带模型明显提高. 莎草科和 麻黄属在植被组模型中较为重要，松属、桤木属和春 黄菊型虽然在花粉组合中相对丰度通常较低，但在区 分 4 个植被组时也起了一定的作用.

总之, 本文研究样点的花粉组合与其湖岸周围 $9 \mathrm{~km}$ 内的植被之间相关性最高. 用随机森林算法建立 的花粉-植被重建模型表现出较高的可靠性, 极有潜力
在今后用于重建青藏高原化石花粉序列对应的古植被 变化.

\section{5 结论}

青藏高原草原带和荒漠带湖泊表层沉积物的现代 花粉组合有相似特征，也存在明显的差别. $\mathrm{A} / \mathrm{C}$ 和 $\mathrm{AP} /$

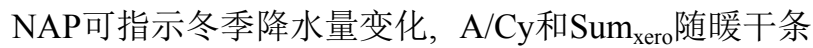
件加强而升高. 采用随机森林算法建立的花粉-植被重 建模型可以根据现代花粉组合极为准确地预测青藏高 原草原带和荒漠带. 当按照层次聚类结果将研究样点 分为 4 个植被组时，随机森林模型的准确率有所下降, 不过仍能有效地重建不同植被类型. 随机森林算法建 立的花粉-植被重建模型极有潜力用在青藏高原地区 基于化石花粉序列重建古植被变化的研究中.

致谢中国科学院地理科学与资源研究所赵艳研究员给 本研究提出建议, 中国科学院青藏高原研究所侯居峙研 究员为本文提供研究材料, 英国University of Hull的M. Jane Bunting博士进行有益讨论, 中国科学院植物研究所 杨健副研究员在数量分析方面给予指导, 河北地质大学 梁琛博士对气候空间插值提供帮助，两位若名审稿人提 出修改意见和建议, 在此一并表示感谢.

\section{参考文献}

唐领余, 毛礼米, 舒军武, 李春海, 沈才明, 周忠泽. 2016. 中国第四纪 狍粉图鉴. 北京: 科学出版社

王伏雄, 钱南芬, 张玉龙, 杨惠秋. 1995. 中国植物花粉形态(第二版). 北京: 科学出版社

王苏民, 窦鸿身. 1998. 中国湖泊志. 北京: 科学出版社

翁成郁，孙湘君，陈因硕．1993．西昆仑地区表土花粉组合特征及其

与植被的数量关系. 植物学报, 35: 69-79

吴绍洪, 尹云鹤, 郑度, 杨勤业. 2005. 青藏高原近 30年气候变化趋势. 地理学报, 60: 3-11

席以珍, 宁建长. 1994. 中国干旱半干旱地区花粉形态研究. 玉山生 物学报, 11: 119-191

张新时．2007．中国植被及其地理格局一一华人民共和国植被图 (1:1000000)说明书. 北京: 地质出版社

张新时. 1978. 西藏植被的高原地带性. 植物学报, 20: 140-149

张镱锂, 李炳元, 郑度. 2014. 《论青藏高原范围与面积》一文数据 的发表一一青藏高原范围界线与面积地理信息系统数据. 地理 学报, 69: 65-68 
中国科学院中国植被图编辑委员会. 2007. 中华人民共和国植被图 (1:1000000). 北京: 地质出版社

An Z S, Kutzbach J E, Prell W L, Porter S C. 2001. Evolution of Asian monsoons and phased uplift of the Himalaya-Tibetan plateau since Late Miocene times. Nature, 411: 62-66

An Z S, Wu G X, Li J P, Sun Y B, Liu Y, Zhou W J, Cai Y J, Duan A M, Li L, Mao J Y, Cheng H, Shi Z G, Tan L C, Yan H, Ao H, Chang H, Feng J. 2015. Global monsoon dynamics and climate change. Annu Rev Earth Planet Sci, 43: 29-77

Birks H J B. 1998. Numerical tools in palaeolimnology—Progress, potentialities, and problems. J Paleolimnol, 20: 307-332

Birks H J B. 2019. Contributions of Quaternary botany to modern ecology and biogeography. Plant Ecol Diversity, 12: 189-385

Birks H J B, Heiri O, Seppä H, Bjune A E. 2010. Strengths and weaknesses of quantitative climate reconstructions based on lateQuaternary biological proxies. Open Ecol J, 279-280: 52-52

Breiman L. 2001. Random forests. Machine Learning, 45: 5-32

Bunting M J, Farrell M, Broström A, Hjelle K L, Mazier F, Middleton R, Nielsen A B, Rushton E, Shaw H, Twiddle C L. 2013. Palynological perspectives on vegetation survey: A critical step for model-based reconstruction of Quaternary land cover. Quatern Sci Rev, 82: 41-55

Cour P, Zheng Z, Duzer D, Calleja M, Yao Z. 1999. Vegetational and climatic significance of modern pollen rain in northwestern Tibet. Rev Palaeobot Palynol, 104: 183-204

El-Moslimany A P. 1990. Ecological significance of common nonarboreal pollen: Examples from drylands of the Middle East. Rev Palaeobot Palynol, 64: 343-350

Gaillard M J, Sugita S, Bunting M J, Middleton R, Broström A, Caseldine C, Giesecke T, Hellman S E V, Hicks S, Hjelle K, Langdon C, Nielsen A B, Poska A, von Stedingk H, Veski S. 2008. The use of modelling and simulation approach in reconstructing past landscapes from fossil pollen data: A review and results from the POLLANDCAL network. Veget Hist Archaeobot, 17: 419-443

Grimm E C. 2011. Tilia 1.7.16. Springfield: Illinois State Museum

Han Y, Liu H Y, Hao Q, Liu X, Guo W C, Shangguan H L. 2017. More reliable pollen productivity estimates and relative source area of pollen in a forest-steppe ecotone with improved vegetation survey. Holocene, 27: 1567-1577

Herzschuh U. 2007. Reliability of pollen ratios for environmental reconstructions on the Tibetan Plateau. J Biogeogr, 34: 1265-1273

Herzschuh U, Birks H J B. 2010. Evaluating the indicator value of Tibetan pollen taxa for modern vegetation and climate. Rev Palaeobot Palynol, 160: 197-208

Herzschuh U, Birks H J B, Mischke S, Zhang C J, Böhner J. 2010. A modern pollen-climate calibration set based on lake sediments from the Tibetan Plateau and its application to a Late Quaternary pollen record from the Qilian Mountains. J Biogeogr, 37: 752-766

Herzschuh U, Winter K, Wunnemann B, Li S. 2006. A general cooling trend on the central Tibetan Plateau throughout the Holocene recorded by the Lake Zigetang pollen spectra. Quat Int, 154-155: $113-121$

Jackson S T, Williams J W. 2004. Modern analogs in Quaternary paleoecology: Here today, gone yesterday, gone tomorrow? Annu Rev Earth Planet Sci, 32: 495-537

Legendre P, Fortin M J. 1989. Spatial pattern and ecological analysis. Vegetatio, 80: 107-138

Li J F, Xie G, Yang J, Ferguson D K, Liu X D, Liu H, Wang Y F. 2020. Asian Summer Monsoon changes the pollen flow on the Tibetan Plateau. Earth-Sci Rev, 202: 103114

Liaw A, Wiener M. 2002. Classification and Regression by randomForest. R News, 2: 18-22

Lisitsyna O V, Hicks S, Huusko A. 2012. Do moss samples, pollen traps and modern lake sediments all collect pollen in the same way? A comparison from the forest limit area of northernmost Europe. Veget Hist Archaeobot, 21: 187-199

Liu H Y, Cui H T, Pott R, Speier M. 1999. The surface pollen of the woodland-steppe ecotone in southeastern Inner Mongolia, China. Rev Palaeobot Palynol, 105: 237-250

Liu H Y, Yi W, Tian Y H, Zhu J L, Wang H Y. 2006. Climatic and anthropogenic control of surface pollen assemblages in East Asian steppes. Rev Palaeobot Palynol, 138: 281-289

Lu H Y, Wu N Q, Liu K B, Zhu L P, Yang X D, Yao T D, Wang L, Li Q, Liu X Q, Shen C M, Li X Q, Tong G B, Jiang H. 2011. Modern pollen distributions in Qinghai-Tibetan Plateau and the development of transfer functions for reconstructing Holocene environmental changes. Quat Sci Rev, 30: 947-966

Lu H, Wu N Q, Yang X D, Shen C M, Zhu L P, Wang L, Li Q, Xu D K, Tong G B, Sun X J. 2008. Spatial pattern of Abies and Picea surface pollen distribution along the elevation gradient in the QinghaiTibetan Plateau and Xinjiang, China. Boreas, 37: 254-262

Luo C X, Zheng Z, Tarasov P, Nakagawa T, Pan A D, Xu Q H, Lu H Y, Huang K Y. 2010. A potential of pollen-based climate reconstruction using a modern pollen-climate dataset from arid northern and western China. Rev Palaeobot Palynol, 160: 111-125

Ma Q F, Zhu L P, Lü X M, Wang Y, Guo Y, Wang J B, Ju J T, Peng P, Tang L Y. 2017a. Modern pollen assemblages from surface lake sediments and their environmental implications on the southwestern Tibetan Plateau. Boreas, 46: 242-253

Ma Q F, Zhu L P, Wang J B, Ju J T, Lü X M, Wang Y, Guo Y, Yang R M, Kasper T, Haberzettl T, Tang L Y. 2017b. Artemisial Chenopodiaceae ratio from surface lake sediments on the central 
and western Tibetan Plateau and its application. Palaeogeogr Palaeoclimatol Palaeoecol, 479: 138-145

Mantel N. 1967. The detection of disease clustering and a generalized regression approach. Cancer Res, 27: 209-220

Molnar P, Boos W R, Battisti D S. 2010. Orographic controls on climate and paleoclimate of Asia: Thermal and mechanical roles for the Tibetan Plateau. Annu Rev Earth Planet Sci, 38: 77-102

Moore P D, Webb J A, Collinson M E. 1991. Pollen Analysis. 2nd ed. Oxford: Blackwell

Oksanen J, Blanchet F G, Friendly M, Kindt R, Legendre P, McGlinn D, Minchin P R, O'Hara R B, Simpson G L, Solymos P, Stevens H H, Szoecs E, Wagner H. 2018. Vegan: Community Ecology Package. R Package Version 2.5-2

Parsons R W, Prentice I C. 1981. Statistical approaches to R-values and the pollen-vegetation relationship. Rev Palaeobot Palynol, 32: 127152

Peng S S, Piao S L, Ciais P, Fang J Y, Wang X H. 2010. Change in winter snow depth and its impacts on vegetation in China. Glob Change Biol, 16: 3004-3013

Prentice I C, Webb T III. 1986. Pollen percentages, tree abundances and the Fagerlind effect. J Quat Sci, 1: 35-43

Qin F, Zhao Y, Li Q, Cai M T. 2015. Modern pollen assemblages from surface lake sediments in northwestern China and their importance as indicators of vegetation and climate. Sci China Earth Sci, 58: $1643-1655$

R Core Team. 2018. R: A language and environment for statistical computing. Vienna: R Foundation for Statistical Computing

Shang X, Li X Q, An Z S, Ji M, Zhang H B. 2009. Modern pollen rain in the Lake Qinghai basin, China. Sci China Ser D-Earth Sci, 52: $1510-1519$

Shen C M, Liu K B, Tang L Y, Overpeck J T. 2006. Quantitative relationships between modern pollen rain and climate in the Tibetan Plateau. Rev Palaeobot Palynol, 140: 61-77

Sobol M K, Finkelstein S A. 2018. Predictive pollen-based biome modeling using machine learning. PLoS ONE, 13: e0202214

Sobol M K, Scott L, Finkelstein S A. 2019. Reconstructing past biomes states using machine learning and modern pollen assemblages: A case study from Southern Africa. Quatern Sci Rev, 212: 1-17

Sugita S. 1994. Pollen representation of vegetation in Quaternary sediments: Theory and method in patchy vegetation. J Ecol, 82: 881-897

Sugita S. 2007a. Theory of quantitative reconstruction of vegetation I: Pollen from large sites REVEALS regional vegetation composition. Holocene, 17: 229-241

Sugita S. 2007b. Theory of quantitative reconstruction of vegetation II: All you need is LOVE. Holocene, 17: 243-257
Sugita S, Gaillard M J, Broström A. 1999. Landscape openness and pollen records: A simulation approach. Holocene, 9: 409-421

The Angiosperm Phylogeny Group. 2016. An update of the Angiosperm Phylogeny Group classification for the orders and families of flowering plants: APG IV. Bot J Linn Soc, 181: 1-20

Wei H C, Ma H Z, Zheng Z, Pan A D, Huang K Y. 2011. Modern pollen assemblages of surface samples and their relationships to vegetation and climate in the northeastern Qinghai-Tibetan Plateau, China. Rev Palaeobot Palynol, 163: 237-246

Wilmshurst J M, McGlone M S. 2005. Origin of pollen and spores in surface lake sediments: Comparison of modern palynomorph assemblages in moss cushions, surface soils and surface lake sediments. Rev Palaeobot Palynol, 136: 1-15

Xu Q H, Zhang S R, Gaillard M J, Li M Y, Cao X Y, Tian F, Li F R. 2016. Studies of modern pollen assemblages for pollen dispersaldeposition-preservation process understanding and for pollen-based reconstructions of past vegetation, climate, and human impact: A review based on case studies in China. Quat Sci Rev, 149: 151-166

Yu G, Tang L Y, Yang X D, Ke X K, Harrison S P. 2001. Modern pollen samples from alpine vegetation on the Tibetan Plateau. Glob Ecol Biogeogr, 10: 503-519

Zhang R, Tian F, Xu Q H, Zhou X, Liu X Q, Cao X Y. 2020. Representation of modern pollen assemblage to vertical variations of vegetation and climate in the Yadong area, eastern Himalaya. Quat Int, 536: 45-51

Zhang Y, Kong Z, Wang G, Ni J. 2010. Anthropogenic and climatic impacts on surface pollen assemblages along a precipitation gradient in north-eastern China. Glob Ecol Biogeogr, 19: 621-631

Zhang Y, Kong Z C, Yang Z J, Wang L, Duan X H. 2017. Surface pollen distribution from Alpine vegetation in Eastern Tibet, China. Sci Rep, 7: 586

Zhang Y J, Duo L, Pang Y Z, Felde V A, Birks H H, Birks H J B. 2018. Modern pollen assemblages and their relationships to vegetation and climate in the Lhasa Valley, Tibetan Plateau, China. Quat Int, 467: $210-221$

Zhang Z Y, Harrison S P, Mosbrugger V, Ferguson D K, Paudayal K N, Trivedi A, Li C S. 2015. Evaluation of the realism of climate reconstruction using the coexistence approach with modern pollen samples from the Qinghai-Tibetan Plateau. Rev Palaeobot Palynol, 219: $172-182$

Zhao Y, Herzschuh U. 2009. Modern pollen representation of source vegetation in the Qaidam Basin and surrounding mountains, northeastern Tibetan Plateau. Veget Hist Archaeobot, 18: 245-260

Zhao Y, Liu H Y, Li F R, Huang X Z, Sun J H, Zhao W W, Herzschuh U, Tang Y. 2012. Application and limitations of the Artemisial Chenopodiaceae pollen ratio in arid and semi-arid China. Holocene, 
22: $1385-1392$

Zhao Y, Xu Q H, Huang X Z, Guo X L, Tao S C. 2009. Differences of modern pollen assemblages from lake sediments and surface soils in arid and semi-arid China and their significance for pollen-based quantitative climate reconstruction. Rev Palaeobot Palynol, 156: $519-524$
Zheng Z, Wei J H, Huang K Y, Xu Q H, Lu H Y, Tarasov P, Luo C X, Beaudouin C, Deng Y, Pan,A D, Zheng Y W, Luo Y L, Nakagawa, T, Li C H, Yang S X, Peng H H, Cheddadi R. 2014. East Asian pollen database: Modern pollen distribution and its quantitative relationship with vegetation and climate. J Biogeogr, 41: 18191832

(责任编委: 李小强) 